\title{
Speed and position estimator of for sensorless PMSM drives using adaptive controller
}

\author{
Jurifa Mat Lazi, Zulkifilie Ibrahim, MHN Talib, Azrita Alias, Ainain Nur, Maaspaliza Azri \\ Department of Power Electronics and Drives, Faculty of Electrical Engineering, \\ Universiti Teknikal Malaysia Melaka (UTeM), Malaysia
}

\begin{tabular}{l}
\hline Article Info \\
\hline Article history: \\
Received Jul 20, 2018 \\
Revised Sep 17, 2018 \\
Accepted Sep 29, 2018 \\
\hline
\end{tabular}

Keywords:

PMSM

Sensorless

Speed estimator

SVPWM

\begin{abstract}
Nowadays, the elimination of the speed sensor in Permanent Magnet Synchronous Machine (PMSM) is greatly recommended to increase efficiency and reduce the cost of the drives. This paper proposes a simple estimator for speed and rotor position of PMSM drives using adaptive controller. The novelties of the proposed method are the simple estimator equations and the absence of the voltage probe which depend on direct and quadrature reference current only. The simplified mathematical model of the PMSM is formulated by using V-I model, based on adaptive control. Then, the speed estimation error of the voltage and current model based are analyzed. Thus, an adaptation mechanism model is established to cancel the error of the measured and estimated d-q currents. Since the output of the estimator is the position feedback, the performances of speed responses are presented. The hardware implementation of proposed sensorless drives is realized via dSPACE DS11103 panel. dSPACE Real Time Implementation (RTI) is the linkage between software and hardware set-up. It automatically processes the MATLAB Simulink model into dSPACE DS11103 processor. The experimental-hardware results demonstrate that the speed and position estimator of the proposed method is able to control the PMSM drives for forward and reverse of speed command, acceleration, deceleration and robustness to load disturbance.
\end{abstract}

Copyright (C) 2019 Institute of Advanced Engineering and Science. All rights reserved.

\section{Corresponding Author:}

Jurifa binti Mat Lazi,

Department of Power Electronics and Drives, Faculty of Electrical Engineering,

Universiti Teknikal Malaysia Melaka,

Hang Tuah Jaya, 76100, Durian Tunggal, Melaka, Malaysia.

Email: jurifa@utem.edu.my

\section{INTRODUCTION}

In PMSM variable speed drives, the feedback of speed and rotor position are compulsory. Usually that information is gathered from position sensor such as incremental encoder and absolute encoder. Unfortunately, the price for available position sensor is quite expensive. Therefore, the elimination of speed sensor in PMSM drives will reduce the total drives cost. The elimination of speed sensor need to be replaced by a sensorless mechanism that can produce the feedback of speed sensor and rotor position measurements. The measurements can be made by using estimator. Generally, estimation of the sensorless method is divided into two categories; which are based on fundamental excitations method and based on signal injection method. In fundamental excitations method, the speed and rotor position are estimated using mathematical representation of the PMSM. It can be divided into two groups; Non-Adaptive method and Adaptive method. Non-Adaptive method is based on measured current and voltage, while Adaptive method employs the correction technique for measured value and actual value through adaption mechanism. Through this method, all the states in the PMSMs drives system can be estimated including the states that are difficult to estimate. 
Non Adaptive method employs the fundamental equations for PMSMs. Different type of fundamental equations are being used by other researchers such as, based on Back Electromagnetic Force (EMF) by [1]-[4]. Voltage and Current based are used by [5],[6] as the fundamental equation. Other than that, [7],[8] are using Instantaneous power based as the fundamental equation. Rotor flux is used as the fundamnetal equation by [4], [9], [10]. For all model based estimator, the main problem is at low speed operation. For zero speed operation, back EMF is relatively small meanwhile the magnets do not induce any voltage. Besides that, the voltage and current signal are quite noisy because of the Pulse Width Modulation (PWM) operation on the power module. These lead to uncertainty and inaccuracy in speed measurement. To overcome this problem, researchers introduce other method in fundamental excitation by using observer and adaptive method. Yet, the introduction of observer and adaptive method still can't fully solve the low speed operation problem, but the performance are better compared with non-adaptive method.

For adaptive method, the sensorless technique employs different type of observer and adaptation mechanism to estimate the speed and rotor position. Through this method, all the states in PMSMs drives sytem can be estimated. In contrast, this method is not perform well in low speed and requires complex algorithm and calculation [8]. Model Reference Adapative Control (MRAC) computes a desired state using two models, which are reference model and adaptive model. The error between the two models is used to estimate the unknown parameter (speed is the unknow parameter) [8], [10]-[13]. Observer based estimator is an estimator using adaptive model with updated gain " $\mathrm{K}$ " constantly. There are a few types of observers that have been used by many researchers, depending on the estimated state variable and the model based of the motor. Among them, J. Solsona et al, [14] used extended nonlinear observer which employs the state observer to estimate the rotor position and speed through torque estimator. Then, J.S Park et al, [7] used position tracking observer based on instantaneous power. This tracking observer gives good results for parameter variations. In 2005, T.D. Batzel and K.Y. Lee, [6] came out with Observer Pole Placement for electric propulsion. Other than that, L. Salvatore and S.Stasi, [15] used an Extended Kalman Filter (EKF) theory for parameters and state estimation of PMSMs drives and the speed responses follow the changes very well. The main problem with EKF is it does not determine the real covariance in nonlinear transformation. To overcome this problem, D.Janiszewski, [16] came out with solution which employs an Unscented Kalman Filter (UKF). This type of filter uses only the measurement of motor current for on-line estimation of speed, rotor position and load torque reconstruction. And M.Preindl and E. Schaltz, [17] chose second order Phase Locked Loop (PLL) observer as the estimator which uses Model Predictive Direct Current Control (MPDCC).

For signal injection method, the feature of salient-PMSMs such as variation of inductance with the rotor position is employed. High frequency voltage or current signal is injected on the top of the fundamental systems meanwhile signal processing (vector filters with predictable time delay) is employed to extract current harmonics that contain rotor position. Therefore, the position still can be estimated even though at standstill and low speed operations. Moreover, the rotor position still can be estimated even at standstill and low speed operation and robustly towards the parameter variations [18]-[21].

This current study introduces a sensorless technique using adaptive model based using differential of $d-q$ currents and voltages to estimate the speed of the motor [22]. The advantages of the proposed method are, the algorithm is very simple yet still achieve a good performance, and the absence of the voltage probe, made this technique more economic then those which use the voltage probe. The basic diagram for overall block diagram is depicted in Figure 1. The figure depicts the overall block diagram of Sensorless Speed Control of PMSM drives using speed and position estimator.

\section{FIELD ORIENTED CONTROL (FOC) OF THREE-PHASE PMSM DRIVES}

The mathematical equations of PMSM are developed with a few assumptions such as parameter changes, the induced EMF is sinusoidal, eddy currents and hysteresis losses are negligible, no field current dynamics and no cage on the rotor. The mathematical model for a PMSM in $d-q$ reference frame can be determined by following equations [1],[10].

$$
\begin{aligned}
& v_{d}=r_{s} i_{d}+\frac{d}{d t} \psi_{d}-\omega_{e} \psi_{q} \\
& v_{q}=r_{s} i_{q}+\frac{d}{d t} \psi_{q}+\omega_{e} \psi_{d} \\
& \text { where: } \begin{array}{l}
v_{d}, v_{q} \quad: d-q \text { axis voltage } \\
i_{d}, i_{q} \quad: d-q \text { axis currents }
\end{array}
\end{aligned}
$$


$\omega_{e} \quad$ : electrical speed of motor

$r_{s} \quad:$ stator resistance

$\psi_{d}, \psi_{q}: d-q$ axis flux linkages

The flux linkages are expressed as stated in (3) and (4).

$\psi_{d}=L_{d} i_{d}+\psi_{m}$

$\psi_{q}=L_{q} i_{q}$

where:

$L_{d}, \quad L_{q}: d-q$ axis inductances

$\psi_{m} \quad$ : flux linkage due to the rotor magnets linking the stator

By substituting (3) and (4) into (1) and (2), the new equations for stator voltages are:

$v_{d}=r_{s} i_{d}+L_{d} \frac{d}{d t} i_{d}-\omega_{e} L_{q} i_{q}$

$v_{q}=r_{s} i_{q}+L_{q} \frac{d}{d t} i_{q}+\omega_{e} L_{d} i_{d}+\omega_{e} \psi_{m}$

The electromagnetic torque is

$T_{e m}=\frac{3}{2} p\left[\psi_{m} i_{q}+\left(L_{d}-L_{q}\right) i_{d} i_{q}\right]$

and,

$T_{e m}-T_{L}=J \frac{d \omega_{e}}{d t}+B \omega_{e}$

where; $P$ : number of pole pairs

$T_{L}:$ load torque

$B$ : damping coefficient

$J$ : moment of inertia

The instantaneous angular position is;

$\omega_{r}=\frac{d \theta}{d t}$

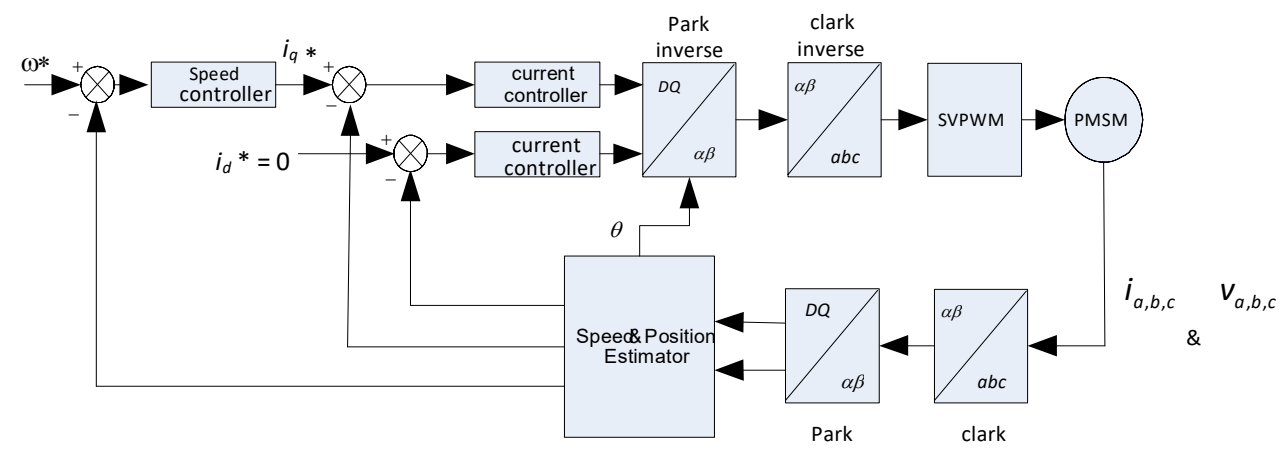

Figure 1. Sensorless speed control of PMSM drives using speed \& position estimator

In vector control, the $d-q$ currents and voltages results in control of the spatial orientation of the electromagnetic fields in the machine and has led to the term of field orientation. Generally, vector control is 
reserved for controllers to maintain a $90^{\circ}$ spatial orientation between critical field components and hence adopt the term field angle control for systems which depart from the $90^{\circ}$. From (3), if $i_{d}$ is forced to be zero, then equation (7) will become;

$$
T_{e}=\frac{3}{2} P \psi_{m} i_{q}
$$

From the (10), the quadrature axis current, $i_{q}$ is proportional to the electromagnetic torque, $T_{e}$. But through (8), the electromagnetic torque is derivative function of speed. Through this relationship, the speed controller can be applied as shown in Fig 1. The speed controller estimates the torque through reference current, $i_{q}{ }^{*}$, then, two current controllers convert the $i_{q}{ }^{*}$ and $i_{d}{ }^{*}$ signals to voltages $\left(V_{q}{ }^{*}, V_{d} *\right)$. These voltages are then, transformed to $\alpha-\beta$ model by using inverse Park's transformation;

$$
\left[\begin{array}{l}
i_{\alpha} \\
i_{\beta}
\end{array}\right]=\left[\begin{array}{cc}
\cos \theta & -\sin \theta \\
\sin \theta & \cos \theta
\end{array}\right]\left[\begin{array}{l}
i_{d} \\
i_{q}
\end{array}\right]
$$

Then, using inverse Clark's equation, $V \alpha^{*}$ and $V \beta^{*}$, are converted to three phase voltages, $V a, V b$, $V c$ through the equation below. Inverse Clark's transformation;

$$
\left[\begin{array}{l}
v_{a} \\
v_{b} \\
v_{c}
\end{array}\right]=\left[\begin{array}{cc}
1 & 0 \\
-\frac{1}{2} & \frac{\sqrt{3}}{2} \\
-\frac{1}{2} & -\frac{\sqrt{3}}{2}
\end{array}\right]\left[\begin{array}{l}
v_{\alpha} \\
v_{\beta}
\end{array}\right]
$$

The $V_{a}, V_{b}$, and $V_{c}$ signals are used to produce SVPWM switching signals before they can be used to drive a PMSM. Then, the output of the PMSM drives are three-phase voltages and currents. These currents and voltages are used in the speed and position estimator. The estimator will produce the estimated value of motor's speed. The estimated rotor position is calculated by integrating the value of the motor speed. Then, the three-phase current of the PMSM are converted to $d-q$ model back by using Clark and Park's transformation as depicted below.

Clark's transformation;

$$
\left[\begin{array}{l}
i_{\alpha} \\
i_{\beta}
\end{array}\right]=\left[\begin{array}{rrr}
\frac{2}{3} & -\frac{1}{3} & -\frac{1}{3} \\
0 & \frac{1}{\sqrt{3}} & -\frac{1}{\sqrt{3}}
\end{array}\right]\left[\begin{array}{l}
i_{a} \\
i_{b} \\
i_{c}
\end{array}\right]
$$

Park's transformation;

$$
\left[\begin{array}{l}
i_{d} \\
i_{q}
\end{array}\right]=\left[\begin{array}{cc}
\cos \theta & \sin \theta \\
-\sin \theta & \cos \theta
\end{array}\right]\left[\begin{array}{l}
i_{\alpha} \\
i_{\beta}
\end{array}\right]
$$

Finally, the actual $i_{d}$ and $i_{q}$ will be compared with the references current to produce the error that will be corrected using adaptive controller.

\section{SPEED AND POSITION ESTIMATOR DESIGN}

Figure 2 shows the configuration of speed and position estimation method. It consists of three-phase to two-phase conversion, adjustable model and adaptation mechanism. The objective of the design is to reduce the noise impact to control and influence the system transient response as small as possible. Initially,

Speed and position estimator of for sensorless PMSM drives using adaptive controller (Jurifa Mat Lazi) 
the three-phase voltage and current are converted to $d-q$ model. Then, the $d-q$ currents and voltages will be used in adjustable model and adaptation mechanism respectively. From (5) and (6), the phase transformation and adjustable model can be expressed as (15) and (16).

$$
\begin{aligned}
& \frac{d}{d t} \hat{i}_{d(k+1)}=\frac{\left(v_{d}{ }^{*}(k)-r_{s} \hat{i}_{d(k)}+\hat{\omega}_{e(k)} L_{q} \hat{i}_{q(k)}\right)}{L_{d}} \\
& \frac{d}{d t} \hat{i}_{q(k+1)}=\frac{\left(v_{q}{ }^{*}(k)-r_{s} \hat{i}_{q(k)}-\hat{\omega}_{e} L_{d} \hat{i}_{d(k)}-\hat{\omega}_{e} \psi_{m}\right)}{L_{q}}
\end{aligned}
$$

where "^" is referring to estimated value

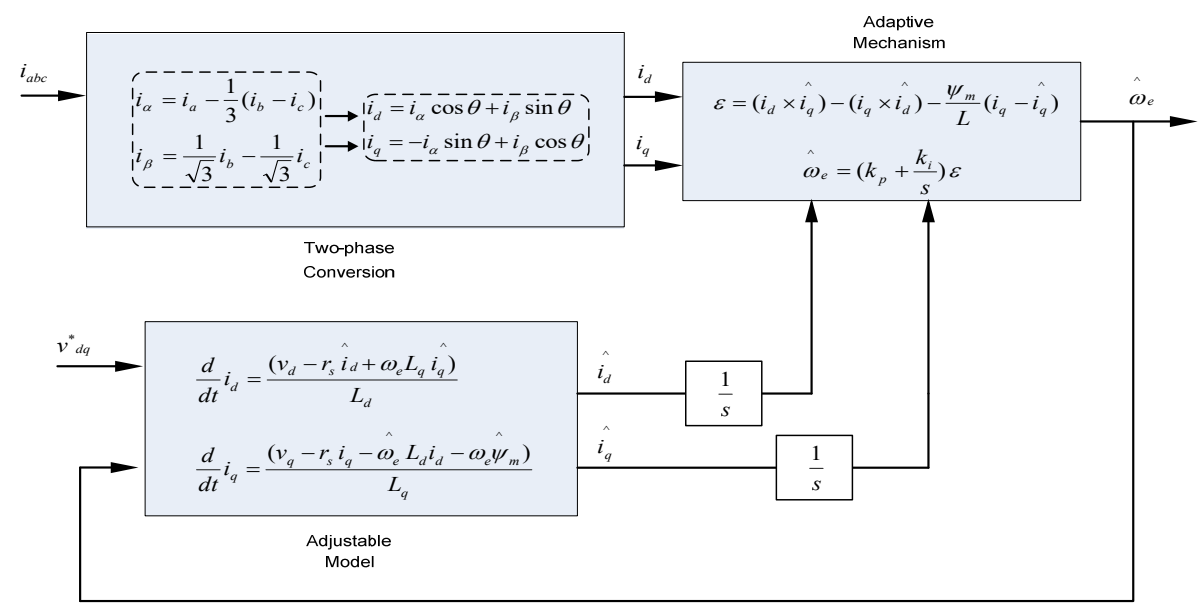

Figure 2. Configuration of speed and position estimator

The output of conversion three-phase model is estimated $d-q$ current which are compared to the actual $d-q$ axis currents. The $i_{d}$ and $i_{q}$ currents are used to calculate the estimated speed using adaptation mechanism. The adaptation mechanism is designed in order to improve the stability and behavior of the adaptive system. It is calculated using Popov's hyper-stability theory to develop the estimated speed as depicted in (17).

$$
\begin{aligned}
& \widehat{\omega}_{e s t}=\left(k_{p}+\frac{k_{i}}{s}\right) \varepsilon \\
& \varepsilon=\left(i_{d} \times \hat{i}_{q \text { est }}\right)-\left(i_{q} \times \hat{i}_{d e s t}\right)-\frac{\psi_{m}}{L}\left(i_{q}-\hat{i}_{q \text { est }}\right)
\end{aligned}
$$

The rotor position is function of derivative of the (9). An estimation error, $\varepsilon$ is defined by (18) and it is derived when the speed used in the current model is not identical to actual model without any influence of parameter variation. A tuning signal for adjustable model is generated from the regulation of this error through a PI controller. The process continues till the error between two outputs tends to zero. The contribution of this technique is the simple mathematical equation for the estimator which based on basic motor parameters only which are; stator resistance $\mathrm{R}_{\mathrm{s}}$, axes inductances $\mathrm{L}_{d}$ and $\mathrm{L}_{\mathrm{q}}$ and flux linkage produced by magnet $\psi_{m}$. Additionally, the estimator does not need any reference model such as in MRAC, in order to get the estimated speed output, which in turn reduced the complexity of the conventional estimator. This technique also, does not utilize the voltage probe, but only using the reference $d-q$ voltage that provided from current controller.

Int J Pow Elec \& Dri Syst, Vol. 10, No. 1, March 2019: $128-136$ 


\subsection{Hardware Implementation}

The hardware set-up of the PMSM drives are presented in Figure 3. It consists of Personal Computer (PC), Voltage Source Inverter (VSI), PMSM and Hall-effect current sensors. The microprocessor board for the system is dSPACE DSP DS1103. The DS1103 is equipped with a TMS320F240 that acts as slave processor for advanced I/O purposes. The power circuit of the drives is using IGBT- based three-phase VSI and gate driver circuits. The PMSM model is BSM90C-2150 manufactured by BALDOR. The details of motor's parameters are shown in Table 1. The simulation and analysis of the PMSM drives are exected using MATLAB/Simulink. The model is downloaded to the input/output connection via Real Time (RTI) library. The implementation of the model is carried out using RTI hardware through dSPACE expansion box. After verification in a real environment, the outputs are measured and controlled through Graphical User Interface (GUI) in dSPACE Control Desk. Then the output of the PMSM drives system such as speed, rotor position and three-phase currents are measured and used as system feedback using dSPACE's Analog to Digital (ADC) ports.

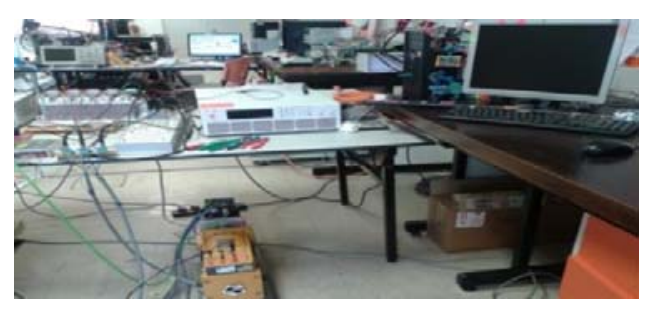

Figure 3. Hardware implementation for sensorless PMSM drives

\section{EXPERIMENTAL RESULTS}

Figure 4 to Figure 6 represent the detailed behavior of speed responses for the proposed method. The motor is tested and experimental results captured are under following different operating conditions:

\subsection{Forward and reverse operation}

Figure 4 shows the robustness of the proposed controller from forward to reverse, and from reverse to forward operations. The PMSM is tested running at $300 \mathrm{rpm}$ (forward) to $-300 \mathrm{rpm}$ (reverse) at $\mathrm{t}=5.5 \mathrm{~s}$ and during $\mathrm{t}=10 \mathrm{~s}$, the PMSM is push to operate from reverse to forward condition. The controller also tested in increase step command condition from 300rpm to 600 rpm. The system gives good speed response without huge overshoot during the transition.

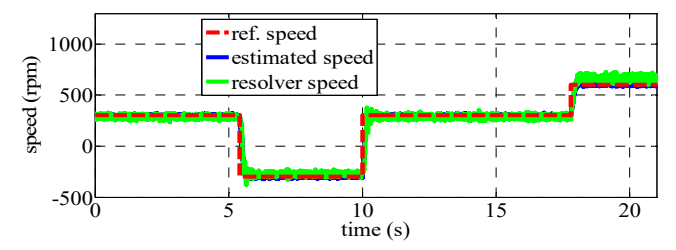

(a)

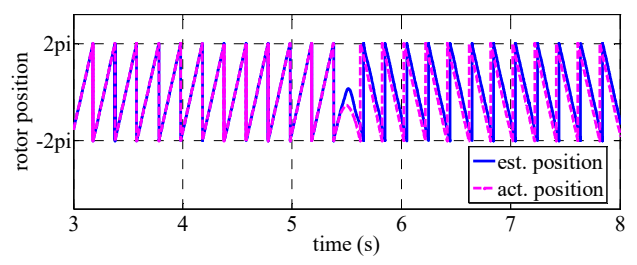

(c)

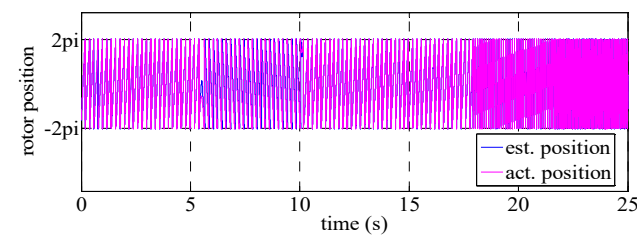

(b)

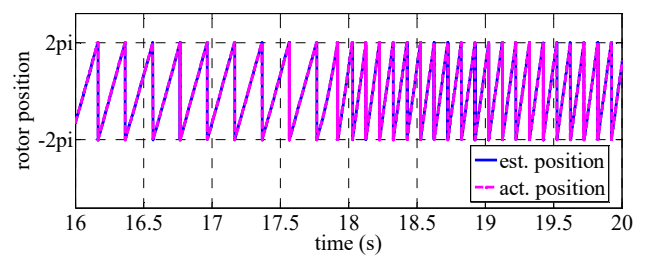

(d)

Figure 4. Experimental results for forward and reverse operation; (a)speed response, (b)rotor position; (c)zoom view for rotor position at $3 \mathrm{~s}<\mathrm{t}<8 \mathrm{~s}$, (reverse operation), (d)zoom view for rotor position at $16 \mathrm{~s}<\mathrm{t}$ $<20$ s (forward operation)

Speed and position estimator of for sensorless PMSM drives using adaptive controller (Jurifa Mat Lazi) 


\subsection{Acceleration}

Figure 5 presents the experimental result for speed acceleration from $180 \mathrm{rpm}$ to $840 \mathrm{rpm}$. The actual and estimated speed responses follow well the reference input. The speed reference starts at 180rpm. This condition happen because the estimator utilizes the direct and quadrature current and voltage equations, makes the estimator unable to calculate the speed during initial condition due to zero magnetizing current and voltage within that time range. In practical, the sensorless need other starter method to move the PMSM. Otherwise, for this current study, the PMSM is started manually and make it synchronize with the estimated speed.

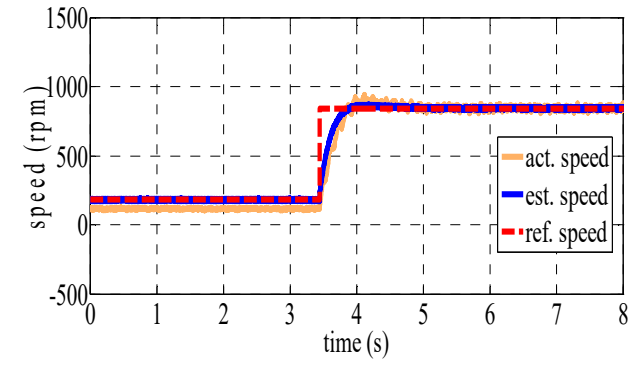

(a)

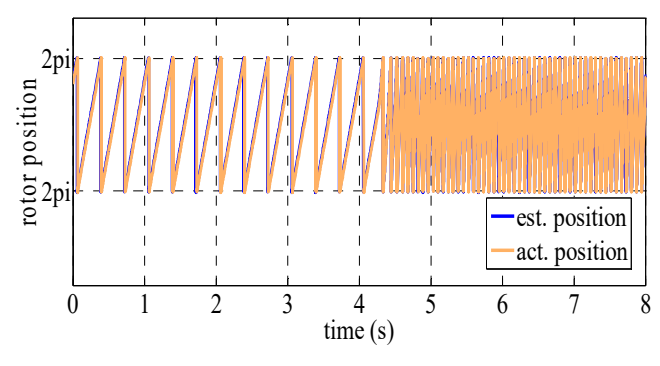

(b)

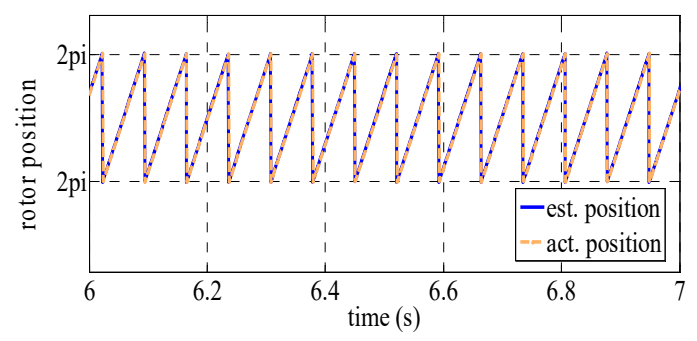

(d)

Figure 5. Experimental results for speed acceleration; (a)speed response ; (b)rotor position ;

(c)zoom view for rotor position at $6 \mathrm{~s}<\mathrm{t}<7 \mathrm{~s}$

\subsection{Load disturbance}

The load rejection capabilities are investigated by applying rated external load disturbance during specified speed. The motor is initially operated under no load condition. The load disturbance is applied at $\mathrm{t}=$ 12s. The PMSM experienced small undershoot during the rejection and able to recover within 1 second. Table 1 shows motor specifications.

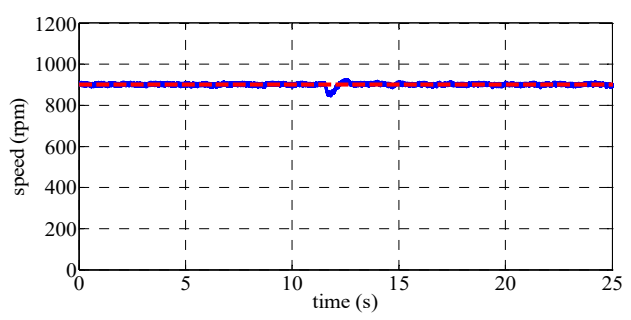

(a)

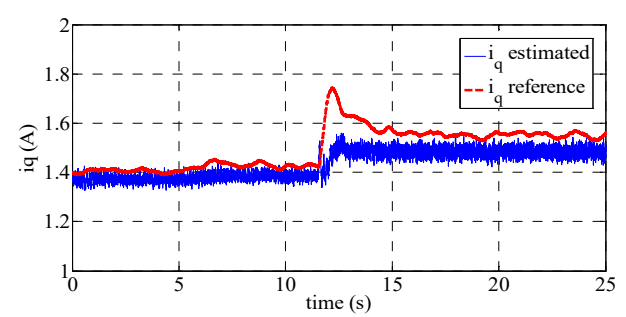

(b) 


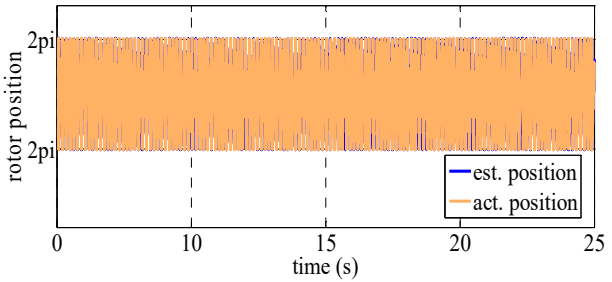

(c)

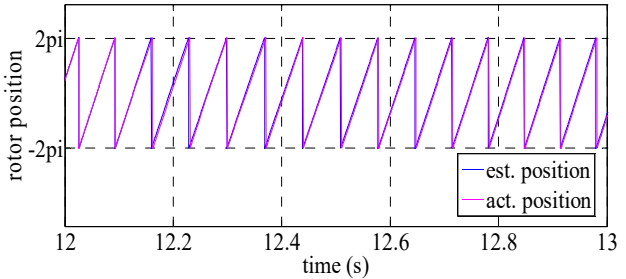

(d)

Figure 6. Experimental results for load disturbance; (a)speed response; (b)quadrature currents; (c)estimated and actual rotor positions ; (d)zoom view for estimated and actual rotor position at $12 \mathrm{~s}<\mathrm{t}<13 \mathrm{~s}$

Table 1. Motor specifications

\begin{tabular}{cll}
\hline Bil & \multicolumn{1}{c}{ PARAMETERS } & \multicolumn{1}{c}{ Values } \\
\hline 1 & Rated Torque & $1.65 \mathrm{Nm}$ \\
2 & Rated Speed & $2000 \mathrm{rpm}$ \\
3 & Number of pole-pairs & 4 \\
4 & Inertia & $0.0003389 \mathrm{kgm}^{2}$ \\
5 & Resistance & $4.33 \Omega$ \\
6 & Inductance & $0.0176 \mathrm{H}$ \\
7 & Magnet Flux & $0.194925 \mathrm{Vs}$ \\
8 & DC Link Voltage & $300 \mathrm{~V}$ \\
\hline
\end{tabular}

\section{CONCLUSION}

The experimental results present the efficiency of the proposed controller for variation of speed and prove that the system can back to steady state condition from the load disturbances. By using speed and position estimator or sensorless speed control, the size and cost of the drive system can be decreased and make this ongoing project significance in the area of machine drive study. The effectiveness of the dSPACE DS1103 board is also gained. The dSPACE board offer "user friendly" features which any changes can be made and controlled without any changes in programming.

\section{ACKNOWLEDGEMENTS}

The author would like to acknowledge "Centre of Robotic \& Industrial Automation" (CERIA), "Centre of Research and Innovation Management" (CRIM), UniversitiTeknikal Malaysia Melaka (UTeM) and Ministry of Higher Education Malaysia (MOHE) for supporting this project.

\section{REFERENCES}

[1] F. Genduso, R. Miceli, C. Rando, and G. R. Galluzzo, "Back EMF sensorless-control algorithm for high-dynamic performance PMSM," Industrial Electronics, IEEE Transactions on, vol. 57, pp. 2092-2100, 2010.

[2] B. Nahid-Mobarakeh, F. Meibody-Tabar, and F.-M. Sargos, "Back EMF estimation-based sensorless control of PMSM: Robustness with respect to measurement errors and inverter irregularities," Industry Applications, IEEE Transactions on, vol. 43, pp. 485-494, 2007.

[3] J. Stumper, D. Paulus, and R. Kennel, "A nonlinear estimator for dynamical and robust sensorless control of permanent magnet synchronous machines," in Decision and Control and European Control Conference (CDCECC), 2011 50th IEEE Conference on, pp. 922-927, 2011.

[4] L. Ying and N. Ertugrul, "A novel, robust DSP-based indirect rotor position estimation for permanent magnet AC motors without rotor saliency," Power Electronics, IEEE Transactions on, vol. 18, pp. 539-546, 2003.

[5] B.-H. Bae, S.-K. Sul, J.-H. Kwon, and J.-S. Byeon, "Implementation of sensorless vector control for super-highspeed PMSM of turbo-compressor," Industry Applications, IEEE Transactions on, vol. 39, pp. 811-818, 2003.

[6] T. D. Batzel and K. Y. Lee, "Electric propulsion with the sensorless permanent magnet synchronous motor: model and approach," Energy Conversion, IEEE Transactions on, vol. 20, pp. 818-825, 2005.

[7] J.-S. Park, S.-M. Jung, H.-W. Kim, and M.-J. Youn, "Design and analysis of position tracking observer based on instantaneous power for sensorless drive of permanent magnet synchronous motor," Power Electronics, IEEE Transactions on, vol. 27, pp. 2585-2594, 2012.

[8] S. Maiti, C. Chakraborty, and S. Sengupta, "Simulation studies on model reference adaptive controller based speed estimation technique for the vector controlled permanent magnet synchronous motor drive," Simulation Modelling Practice and Theory, vol. 17, pp. 585-596, 2009. 
[9] N. Ertugrul and P. Acarnley, "A new algorithm for sensorless operation of permanent magnet motors," Industry Applications, IEEE Transactions on, vol. 30, pp. 126-133, 1994.

[10] M. Rashed, P. F. MacConnell, A. F. Stronach, and P. Acarnley, "Sensorless indirect-rotor-field-orientation speed control of a permanent-magnet synchronous motor with stator-resistance estimation," Industrial Electronics, IEEE Transactions on, vol. 54, pp. 1664-1675, 2007.

[11] S. Maiti, C. Chakraborty, Y. Hori, and M. C. Ta, "Model reference adaptive controller-based rotor resistance and speed estimation techniques for vector controlled induction motor drive utilizing reactive power," Industrial Electronics, IEEE Transactions on, vol. 55, pp. 594-601, 2008.

[12] Z. Ibrahim, J. M. Lazi, and M. Sulaiman, "Independent speed sensorless control of dual parallel PMSM based on Five-Leg Inverter," in Systems, Signals and Devices (SSD), 2012 9th International Multi-Conference on, pp. 1-6, 2012.

[13] J. M. Lazi, Z. Ibrahim, M. Yusoff, S. N. M. Isa, N. M. Yaakop, and A. S. A. Hasim, "Sensorless Speed Control of Independent Dual-PMSM Drives Fed by a Five-Leg Inverter," Australian Journal of Basic and Applied Sciences, vol. 6, pp. 99-110, 2012.

[14] J. Solsona, M. I. Valla, and C. Muravchik, "Nonlinear control of a permanent magnet synchronous motor with disturbance torque estimation," Energy Conversion, IEEE Transactions on, vol. 15, pp. 163-168, 2000.

[15] L. Salvatore and S. Stasi, "Application of EKF to parameter and state estimation of PMSM drive," Electric Power Applications, IEE Proceedings B, vol. 139, pp. 155-164, 1992.

[16] D. Janiszewski, "Sensorless control of Permanent Magnet Synchronous Motor based on Unscented Kalman Filter," in Power Engineering, Energy and Electrical Drives (POWERENG), 2011 International Conference on, pp. 1-6, 2011.

[17] M. Preindl and E. Schaltz, "Sensorless model predictive direct current control using novel second-order PLL observer for PMSM drive systems," Industrial Electronics, IEEE Transactions on, vol. 58, pp. 4087-4095, 2011.

[18] F. M. De Belie, P. Sergeant, and J. A. Melkebeek, "A sensorless drive by applying test pulses without affecting the average-current samples," Power Electronics, IEEE Transactions on, vol. 25, pp. 875-888, 2010.

[19] G. Foo and M. Rahman, "Sensorless sliding-mode MTPA control of an IPM synchronous motor drive using a sliding-mode observer and HF signal injection," Industrial Electronics, IEEE Transactions on, vol. 57, pp. 1270-1278, 2010.

[20] V. Petrovic, A. M. Stankovic, and V. Blasko, "Position estimation in salient PM synchronous motors based on PWM excitation transients," Industry Applications, IEEE Transactions on, vol. 39, pp. 835-843, 2003.

[21] R. Raute, C. Caruana, C. S. Staines, J. Cilia, M. Sumner, and G. M. Asher, "Analysis and compensation of inverter nonlinearity effect on a sensorless PMSM drive at very low and zero speed operation," Industrial Electronics, IEEE Transactions on, vol. 57, pp. 4065-4074, 2010.

[22] A. Rajasekhar, R. K. Jatoth, A. Abraham, and V. Snasel, "A novel hybrid ABF-PSO algorithm based tuning of optimal FOPI speed controller for PMSM drive," in Carpathian Control Conference (ICCC), 2011 12th International, pp. 320-325, 2011.

Int J Pow Elec \& Dri Syst, Vol. 10, No. 1, March 2019: 128 - 136 